\title{
What is the Relationship Among Wages, Supplementary Labor Income, Unemployment and Productivity? _Evidence From Canadian Manufacturing
}

\author{
Huixuan Xie * \\ Faculty of Arts (Department of Economics) University of Alberta, Linyi 276000, China \\ *Corresponding author. Email: xiehuixuan213@163.com
}

\begin{abstract}
This study investigated the relationship between the labor wage (LC), supplementary labor income (SLI), unemployment rate (UN), and labor productivity (LP) of the manufacturing industry in Canada, using time-series econometric techniques. This study was based on the Vector Autoregression Model (VAR) and applied Granger causality Wald tests. Then tested the validity and stability of the model. The results show that all variables did not significantly affect productivity except the first order of itself and labor wages, which indicated that increasing wages improve the passions for work. Moreover, the positive relation between LW and UN presented that the ascending cost of labors decreased the demand of workers, so the unemployment rate raised. However, SIL, which is the difference between LW and labor compensation, ignoring the self-employed income, followed the converse results of LW. The first-order lag of productivity drove a decrease in the unemployment rate. Therefore, policymakers in the manufacturing industry could reconsider the relationships described in this study to adjust productivity and unemployment effectively.
\end{abstract}

Keywords: Productivity, Labor wage, Supplementary labor income, Unemployment rate, Manufacturing industry, Canada.

\section{INTRODUCTION AND BRIEF LITERATURE REVIEW}

The New Keynesianism pointed out that employment is considered to be determined by the sticky labor wage. Besides, studies from Benigno (2015) or other economists also prove the relationship between unemployment and productivity. However, fewer economists studied the relation that labor compensation and productivity are regarded as the determinants of unemployment, which might provide some new approaches to control the unemployment rate in the manufacturing industry of Canada. Also, most studies focused on wages and salaries, ignoring the vital role of supplementary labor income, which is also a part of labor compensation.

Manufacturing is a vital sector of the Canadian economy. It contributes a lot to the gross domestic product (GDP), employment, Research \& Development (R\&D), and exports. For example, it produced $\$ 165$ billions of GDP and provided more than two million jobs in Canada in 2002 (Au, 2004). Hence, it is essential to improve productivity in the manufacturing industry to drive the growth of the economy in Canada and monitor the unemployment rate to keep the economy stable. Therefore, based on this proposed conclusion, this paper attempts to answer the question: Are there any important nexus among the division of labor compensation, unemployment and productivity in the manufacturing industry of Canada? To answer this question, build the model using various econometric methods and test its mobility. Meanwhile, apply Granger causality Wald tests and do the model stability tests. In the next subsection, we present a brief review of past literature talking about the mutual influence between unemployment and productivity and the interaction among wage, supplementary income, unemployment and productivity in various sectors of different countries. The remainder of this paper is as follows. Section 2 displays the data utilized and the 
research methodology. Section 3 reports and tests results. Section 4 discusses the results and limitations. The last section summaries the main findings of the research and presents the conclusion.

\subsection{Brief Literature Review}

First, define the labor wages, supplementary labor income, productivity and unemployment, and then collect arguments from previous literature.

\subsubsection{Defining Labor Wages, Supplementary Labor Income, Productivity and Unemployment}

In the literature, the nominal wages can be classified as exhaustive and comprehensive by including all kinds of compensations or covering all workers in the economy respectively (Sharpe et al., 2008). This study chose the labor wages per hour and labor supplementary per hour instead of only the employee's salaries since labor compensation is an exhaustive measure of wages. Labor compensation is defined as the compensation that includes all payments in cash or a kind of return provided by Canadian producers to workers for their services (Baldwin et al., 2007). Labor wages are the usual wages or salaries of employees at their primary job including tips, commissions, and bonuses before taxes and other deductions (Statistics Canada, 2020). Sharpe (2008, P26) showed the explanation of SLI from Statistic Canada that it is the other expenditure from employers on the labor account including employee welfare funds, unemployment insurance, pension funds and workers' compensation. In this study, the selfemployed worker's income is ignored because the population of self-employed workers in manufacturing in Canada occupied only $4 \%$ of total employees in 2000 and took up $3.9 \%$ in 2019 , which held very little influence on the total. Sharpe (2008) clarified that it is essential to use the exhaustive and comprehensive wage measure owing to comprehensiveness so that it is more appropriate to exam the relationship between labor productivity and labor wages. Besides, the unemployment rate is commonly defined as the number of unemployed persons expressed as a percentage of the labor force (Statistic Canada, 2020). Theoretically, labor productivity is wildly accepted as the ratio between real GDP and hours worked (Statistic Canada, 2020). The wages, supplementary labor income, productivity and unemployment rate data used in this paper were based on these basic definitions.

\subsubsection{International Literature}

From the past literature, economists could search different relations among wages, unemployment and productivity by using diverse methodologies or searching for different industries of different countries. Karaalp-Orhan(2017) found the bi-directional causality between productivity and unemployment rate and the influence of unemployment on productivity and real wages in Turkey. The co-integrated coefficient showed that wages have a positive effect on productivity, while unemployment negatively affected productivity (Ozturk et al., 2020).

Several studies reported the influence of change in labor wages on productivity. Ozturk and other cooperators (2020) held that the wages positively affect productivity since the increase in wages stimulates the awareness of the productivity-based wages and also increases the loyalty and trust to employers. Similarly, Alexander (1993) pointed out that productivity would increase if the labor wage is based on performance. However, in Policardo, Punzo, and Carrera's study (2019), wage inequality negatively affects productivity because of worker's belief of unfairness, but productivity continues to increase before the wages increase to an appropriate level. Besides, Wakeford's (2004) study in South Africa applied the vector autoregression(VAR) with two lags to find the cointegrating relation between wages and productivity, which further showed that real wages have a negative influence on productivity, but productivity does not impact on wages.

A review of the available literature shows the various relationships between unemployment and productivity. The workforce loses productivity due to the fear of losing jobs in the construction industry of New Zealand (Ozturk et al., 2020). Similarly, Benigno, Ricci and Surico (2015) used panel data from the American labor market with sticky real wages showing that unemployment and productivity are negatively related in the long-run. However, Wakeford's study (2004) indicated a weak relation between the unemployment rate and productivity in the labor market of South Africa. Conversely, the association between these two variables could be changed into significantly positive because of the sticky price, search and matching frictions and variable labor effort (Barnichon, 2010). The increasing anxiety of losing jobs might promote productivity owing to the ascending risk of losing job.

In terms of the influence on unemployment, the research results evidence that a rise in productivity could decrease the unemployment rate as the increased efficiency of workers stimulates investments, leading to the increased demand of workers (Karaalp-Orhan, 2017). Conversely, Gallegati and his coauthor (2014) found the positive between these two items because industries substituted labors to machines owing to the rapid technological progress. Also, a wage-setting shock leads to a decrease in labor demand so that the results of increasing productivity with an increased unemployment rate had been found in Chen's studies in 2018. It seems the negative relation is the common 
relation between unemployment and productivity as both wage-setting shock and technology were factors other than productivity; they are only accompanied by the increase in productivity when acting on the unemployment rate. Considering wages, unemployment would arise if the speed of real wages growth exceeds productivity growth because capital replaced the expensive workers (Karaalp-Orhan, 2017). Therefore, there were various relations among these three variables when the studies examine these connections in different industries, diverse countries or even different times. These evidences could bring more ideas about adjusting the economy effectually in manufacturing in Canada.

\section{VARIABLES AND METHODOLOGY}

The model variables are the labor wages, supplementary labor income, productivity and unemployment rate in the manufacturing sector of Canada. Labor productivity is measured as real GDP per hour in the manufacturing sector, the unemployment rate is the total amount of unemployed people divided by the total labor force accounting in thousands, wages are the total compensation per hour worked, supplementary labor income is another part of labor income except wages. The time-series data of these four variables are accessible on the Statistic Canada, limited by the time series from 2000 to 2019 quarterly. The long length of time makes the data of unemployment rate available because unemployment would not fluctuate significantly in the short run. This study used the logarithmic value of wages and supplementary labor income to ensure the stability of data. The software application used to analyze the data was Stata. All data came from the Statistic Canada and Fred.

The relationships among these four variables were investigated as follows. First, verify the endogenous variables and exogenous variables using Granger causality Wald tests. Then, assure the optimal lag length and estimate VAR to build the relation of productivity on labor wage, supplementary labor income and unemployment, and the model of unemployment rate vs. four variables. The next step is to do the stability test to identify the reliability of the final model.

\section{RESULTS}

The results contain preliminary data analysis and more details of final conclusion through constructing the VAR model.

\subsection{Preliminary Data Analysis}

A preliminary analysis of the data could help to predict the model and connect to the real economy. Therefore, the following subsection shows several graphs of these four variables. These graphs are the time series plot of four variables. It is clear that the unemployment rate witnessed a sharp increase in the last two quarters in 2008, while the unemployment experienced a dramatic increase in 2008, which indicates the manufacturing sector suffered from great devastation of the economic crisis in Canada in 2008. The sharp rise in the unemployment rate corresponded to a dramatic drop in supplementary labor income at a similar time. Labor wages had been on an upward trend, which was less affected by the crisis. Labor wages increased following a similar trend like productivity.

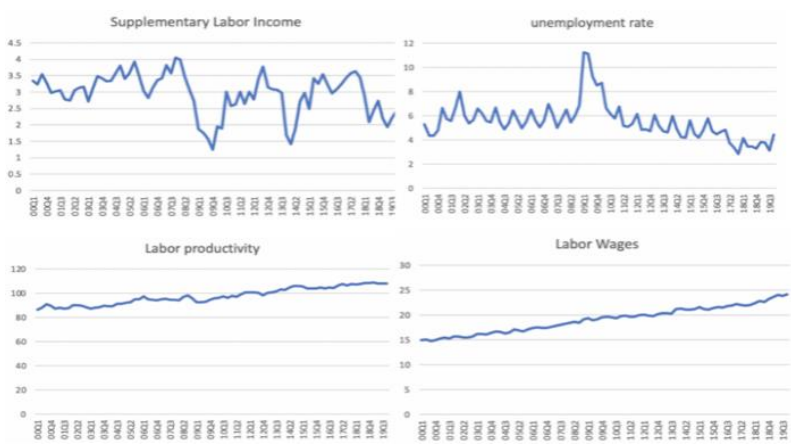

Figure 1 Labor compensations, productivity, unemployment, 2000-2019.

\subsection{Constructing VAR Model}

In order to identify the relationship among productivity, unemployment, labor wages and supplementary labor income, VAR was used to analyze data over the whole period (2000 Q1-2019 Q4) in this section. The logarithmic values of wages and supplementary labor income were used in the model. Firstly, applied the Granger causality Wald tests. From the outcome, wage and suppl were insignificant being endogenous variables, so they were considered as exogenous variables, while produ and unemploy are endogenous variables.

Table1. Variables

\begin{tabular}{|c|c|c|}
\hline Variables & Natural log & Type \\
\hline $\begin{array}{l}\text { Productivity Index } \\
\qquad(2012=100)\end{array}$ & produ & Endogenous \\
\hline Unemployment rate & unemploy & Endogenous \\
\hline Labor wage & $\begin{array}{c}\text { Wage } \\
\text { (LnLabor wage) }\end{array}$ & Exogenous \\
\hline $\begin{array}{l}\text { Supplementary } \\
\text { Labor Income }\end{array}$ & $\begin{array}{c}\text { Suppl } \\
\text { (LnSupplementary } \\
\text { Labor Income) }\end{array}$ & Exogenous \\
\hline
\end{tabular}


Table 2. Testing for Omission

\begin{tabular}{|c|c|c|c|c|c|c|c|c|}
\hline Lag & LL & LR & df & $p$ & FPE & AIC & HQIC & SBIC \\
\hline 0 & -251.14 & & & & 2.97772 & 6.76683 & 6.84037 & 6.95083 \\
\hline 1 & -209.264 & $83.751^{*}$ & 4 & 0.000 & $1.09936^{*}$ & $5.7701^{*}$ & $5.89267^{*}$ & $6.07678^{*}$ \\
\hline 2 & -206.647 & 5.233 & 4 & 0.264 & 1.14088 & 5.80651 & 5.9781 & 6.23586 \\
\hline 3 & -202.063 & 9.1696 & 4 & 0.057 & 1.12479 & 5.79112 & 6.01173 & 6.34314 \\
\hline 4 & -199.233 & 5.6589 & 4 & 0.226 & 1.16215 & 5.82193 & 6.09157 & 6.49662 \\
\hline
\end{tabular}

Table 3. VER Results

\begin{tabular}{|c|c|c|c|c|c|}
\hline $\begin{array}{l}\text { Dependent } \\
\text { variables }\end{array}$ & $\begin{array}{l}\text { Independent } \\
\text { variables }\end{array}$ & Coefficients & $\begin{array}{l}\text { Standard } \\
\text { error }\end{array}$ & Test statistic(z) & P-value \\
\hline \multicolumn{6}{|l|}{ produ } \\
\hline & produ L1. & 0.7252002 & 0.0871929 & 8.32 & 0.000 \\
\hline & unemploy L1. & -0.154687 & 0.1326458 & -1.17 & 0.244 \\
\hline & wage & 12.79355 & 4.137915 & 3.09 & 0.002 \\
\hline & suppl & 0.8425913 & 0.6931911 & 1.22 & 0.224 \\
\hline & _cons & -38.12922 & 12.41222 & -3.07 & 0.002 \\
\hline \multicolumn{6}{|l|}{ unemploy } \\
\hline & produ L1. & -0.1783926 & 0.0641109 & -2.78 & 0.005 \\
\hline & unemploy L1. & 0.4737275 & 0.0975314 & 4.86 & 0.000 \\
\hline & wage & 5.560426 & 3.042513 & 1.83 & 0.068 \\
\hline & suppl & -1.172354 & 0.5096874 & -2.30 & 0.021 \\
\hline & _cons & -12.68996 & 9.126416 & -1.39 & 0.164 \\
\hline Equation & prob & \multicolumn{2}{|l|}{ unemploy } & & \\
\hline RMSE & 1.21185 & \multicolumn{2}{|l|}{0.891047} & AIC & 5.814792 \\
\hline R-Squared & 0.9696 & \multicolumn{2}{|l|}{0.6802} & HQIC & 5.934953 \\
\hline Chi2-stat. & 2521.716 & \multicolumn{2}{|l|}{168.0088} & FPE & 1.149557 \\
\hline P-value & 0.0000 & \multicolumn{2}{|l|}{0.0000} & SBIC & 6.114722 \\
\hline
\end{tabular}


In Next, to select the optimal lag length of variables, the test was based on the following criteria which were shown in Table2. It was based on Likelihood Ratio (LR), Final prediction error (FPE), Akaike information criterion (AIC), Hannan-Quinn information criterion (HQIC) and Schwarz information criterion (SBIC). The optimal lag length is 1 in the light of these selectionorder criteria. Besides, “*” indicates lag is significant which is selected as the optimal lag length.

Then, Table 3 shows the final vector autoregression model with a first-order lag. The first lag of productivity and wages had a positively significant effect on productivity. However, in terms of the unemployment rate, the first lag of productivity and supplementary labor income were negatively related to it, but labor wages and first-lag of unemployment rate positively affected it. Therefore, the VER estimated model refer to the coefficients below:

produ $=-38.12922+0.7252002$ produ L1. -0.154

687unemploy L1. +12.79355wage + 0.8425913sup -pl

unemploy $=-12.68996-0.1783926$ produ L1. +0 .

4737275 unemploy L1. +5.560426wage - 1.172354

suppl

Finally, the stability test results showed that all the eigenvalues lie inside the unit circle so that var satisfies stability condition. Figure 2 represents the circle.

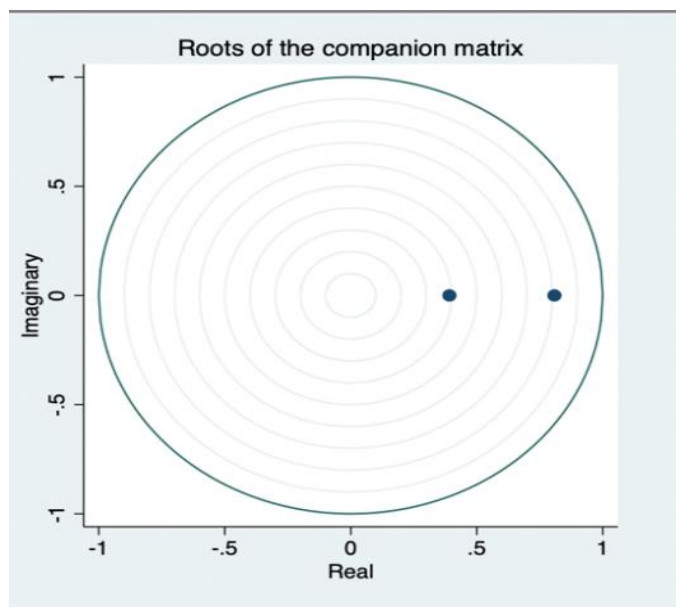

Figure 2 Roots of the companion matrix.

\section{DISCUSSION}

The key findings of this study aiming to find the relationship among labor wages, supplementary labor income, unemployment rate and productivity in manufacturing in Canada are shown as follows. First, productivity was only significantly affected by labor wages. Second, there was a negative relationship between the unemployment rate and the first-order lag of productivity. Similarly, supplementary labor income also showed a negative relationship against the unemployment rate, while labor wages were positively related to the unemployment rate.

In light of the ultimate results, only labor wages had a significant positive effect on productivity, but no other variables could be declared influential, although some economists had found the various relationships between unemployment and productivity. The result is consistent with what Alexander (1993) and Ozturk and other cooperators (2020) had found. Hence, it further proved some economists' speculation that the ascending performance-based real wages would induce an increase in productivity, which also means higher wages would give workers motivation to work efficiently. Besides, it showed that there was no labor inequality, or its effect was very small in manufacturing in Canada. According to the previous literature, the conclusion that the unemployment rate dropped when productivity raised could be applied in manufacturing not only because of the increased investment but also the excellent production prospects decreased the risk of dismission with enough funds so there was the first-order lag of productivity affecting the unemployment rate. Following the final results concerning labor wages, labor wages positively affected the unemployment rate, indicating that more capital might be used instead of the costly labors. Besides, the supplementary labor income followed an inverse relation. The results of this study gave some proofs for some conclusions in previous research in different industries or different countries, compared them with the manufacturing in Canada, offered more comprehensive results in terms of the labor compensation. It provided more information to policymakers in manufacturing in Canada about which part of labor compensation should be adjusted to modulate the unemployment rate efficiently and to increase productivity effectively.

There are some limitations to this study. As mentioned above, these results could be different when it analyzes databases from different countries or various industries. Besides, the effect of self-employed labor income was omitted since self-employed workers accounted for a small proportion of the total labor force in manufacturing in Canada between 2000 and 2019, but it can occupy a large proportion in other industries like construction or wholesale and retail trade. Therefore, the final results could not be generalized to every situation.

\section{CONCLUSION AND POLICY IMPLICATIONS}

With the aid of a simple econometric model, the study demonstrated a relation among productivity, labor wages, supplementary labor income and unemployment in the manufacturing sector of Canada from 2000 to 2019. Granger causality Wald test was used and constructed a vector autoregression model (VAR). The 
results might suggest that labor wages and also the first lag of productivity positively affected productivity, while other variables did not significantly affect productivity. This result ties nicely with some previous studies such as Alexander's finding (1993), while the results contradict the claims of Wakeford (2004) that wage negatively affects productivity because of the adoption of job-shedding technology and capital intensification in South Africa. It is generally understood that the variables of the previous period would cause an additive change for the same variables in the current period. Another result shows both supplementary labor income and the first-order lag of productivity are negatively related to the unemployment rate; nevertheless, the unemployment rate was positively affected by labor wages. This outcome could be analyzed with labor demand and opportunity costs in the labor market. Although commonly accepted, the study was affected by some restrictions including the limits of industry, time length and distinct economic state of various countries. At most, it can only help make some hypotheses to similar data concerned, but it might be useful to consider these results in applied economics. The effects of labor wages on the unemployment rate were less than that of labor wages on productivity, and the unemployment rate was not significantly related to productivity, which might indicate the cost of layoff is lower than that of raising salaries. An increase in wages including insurance and other welfare strengthens the employees' loyalty and the concept of connection of wages with productivity so that stimulates them to work hard. Keeping high productivity in the last year was a benefit to the employment in the current year; similarly, employment could also be raised by increasing the synchronous supplementary labor income.

While the results from this study are similar to most previous studies, policymakers in the manufacturing sector of Canada could also get some idea of improving productivity by adjusting labor wages. Besides, it might help policymakers to balance unemployment affected by wages through changing previous productivity and supplementary labor income. According to the study, the influence of supplementary labor income on the unemployment rate was greater than previous productivity on the unemployment rate, so policymakers could give priority to adjustment of supplementary labor income. However, the negative effects of these two variables on unemployment were weaker than the positive effect of wages, so further research could study another effective factor influencing unemployment and add the self-employed income, which might come to different results. Therefore, policymakers could clearly know what factors and which parts of labor compensation should be adjusted to improve productivity and adjust unemployment.

\section{REFERENCES}

[1] Alexander, C. O. (1993). The changing relationship between productivity, wages and unemployment in the UK. Oxford Bulletin of Economics and Statistics, 55(1), 87-102.

[2] Au, E. (2004). Importance of the Manufacturing Sector to the Canadian Economy.

[3] Baldwin, J. R., Gu, W., \& Yan, B. (2007). User Guide for Statistics Canada's Annual Multifactor Productivity Program. Canadian Productivity Review Research Paper, (14).

[4] Benigno, P., Ricci, L. A., \& Surico, P. (2015). Unemployment and productivity in the long run: the role of macroeconomic volatility. Review of Economics and Statistics, 97(3), 698-709.

[5] Barnichon, R. (2010). Productivity and unemployment over the business cycle. Journal of Monetary Economics, 57(8), 1013-1025.

[6] Chen, P., \& Semmler, W. (2018). Short and long effects of productivity on unemployment. Open Economies Review, 29(4), 853-878.

[7] Gallegati M., Gallegati M., Ramsey J.B., Semmler W. (2014). Does Productivity Affect Unemployment? A Time-Frequency Analysis for the US. In Wavelet applications in economics and finance, 23-46.

[8] Hernandez, R. (2018). The fall of employment in the manufacturing sector. Monthly Labor Review, 141, 1.

[9] Karaalp-Orhan, H. S. (2017). Labour productivity, real wages and unemployment: An application of bounds test approach for Turkey. Economic and Social Development: Book of Proceedings, 4(2), 521-530.

[10] OECD. (2018). The role of collective bargaining systems for good labour market performance. OECD Employment Outlook 2018.

[11] Ozturk, M., Durdyev, S., Aras, O. N., Ismail, S., \& Banaitienè, N. (2020). How effective are labor wages on labor productivity? An empirical investigation on the construction industry of NewZealand. Technological and Economic Development of Economy, 26(1), 258-270.

[12] Policardo, L., Punzo, L. F., \& Carrera, E. J. S. (2019). On the wage-productivity causal relationship. Empirical Economics, 57(1), 329-343.

[13] Sharpe, A., Arsenault, J. F., \& Harrison, P. (2008). The relationship between productivity and 
real wage growth in Canada and OECD countries.

Ottawa: Centre for the Study of Living Standards.

[13] Wakeford 1, J. (2004). The productivity-wage relationship in South Africa: an empirical investigation. Development Southern Africa, 21(1), 109-132 